3. Куликов С.Н., Тюрин Ю .А., Долбин Д.А. и др. Роль структуры в биологической активности хитозина // Вестник Казанского технологического университета, 2007, № 6. - С. 10-15.

4. Марупов А. Экологические чистые технологии защиты хлопчатника от вертициллезного вилта в Узбекистане. Ташкент - 2003. - 246 с.

5. Рашидова Д.К. Применение биологически активных полимеров на хлопчатнике. - Ташкент, 2015. - 132 с.

6. Соколова Е.А., Байданова Е.А. Влияние фиторегуляторов на количество зерен в колосе. Материалы седьмой международной конференции. Санкт-Петербург-Репино, 15-18 сентября 2003 г. - С.114-116.

DOI 10.18699/GPB2020-67

\title{
Изменчивость качественных параметров волокна у гибридов хлопчатника географически отдаленного происхождения
}

Сейтназарова T. *, м.н.с., Эгамбердиева С.А., д.с.-х.н., с.н.с. Научно-исследовательский институт селекиии, семеноводства и агротехнологии вырашивания хлопка, Ташкентская область, Узбекистан. *e-mail: s.tillahon@mail.ru

Изучень длина, удельная разрывная нагрузка, микронейр и расчетная прочность пряжи у гибридов $F_{2}-F_{3}$ хлопчатника, полученных в результате географически отдаленной гибридизаџии в условиях Ташкентской области. Выделены комплексно-ценные комбиначии по качеству волокна.

Ключевые слова: Gossypium hirsutum L., гибрид, верхняя полусредняя длина, микронейр, удельная разрывная нагрузка волокна, SCI.

\section{Variability of qualitative fiber parameters in hybrids of geographically remote origin.}

Seytnazarova Tillakhon Elmuratovna, Cotton breeding, seed production and agricultural technology research institute, 111218 Tashkent, Uzbekistan.

The length, spinning consistency index, micronaire, and the calculated strength of yarn in cotton hybrids F2-F3 obtained as a result of geographically distant hybridization in the conditions of the Tashkent region were studied. Complex-valuable combinations of fiber quality are highlighted.

Key words: Gossypium hirsutum L., hybrid, length, micronaire, SCI.

Сорта хлопчатника должны обладать комплексом хозяйственно-ценных признаков и удовлетворять по качеству волокна быстроразвивающуюся 
текстильную промышленность. Источниками улучшения генетической основы возделываемых сортов хлопчатника являются, как известно, генофонд диких видов, рудеральных форм, обладающие донорскими свойствами по устойчивости к вертициллезу, качеству волокна и другим признакам $[1,3]$.

Полученные ранее интрогрессивные линии Л-Т - $\mathrm{F}_{15} \mathrm{BC}_{4}(G$. hirsutum L., сорт C-4727 x G. trilobum Skovsted) х C-4727, Л-Ю - $\mathrm{F}_{11} \mathrm{BC}_{3}$ (G. hirsutum L., copт Delkott 277x G. hirsutum ssp. yucatanense) х Л-77, линия Л-578 производная от Л-Т служили материнскими формами [4]. В качестве отцовских форм были взяты сорта из США и Австралии. Статистическая обработка данных проводилась методом дисперсионного анализа по Б.А. Доспехову. Анализы качества волокна проводили на приборе HVI. Цель исследования изучить изменчивость признаков качества волокна у гибридов второго и третьего поколения, полученных от скрещивания географически отдаленных форм хлопчатника.

Наиболее важными характеристиками волокна являются длина, микронейр и удельная разрывная нагрузка волокна [5]. Длина волокна из всех качественных признаков имеет наибольшее значение в определении его технологической ценности. Для характеристики этого показателя на приборе HVI (High Volume Instrument) принят параметр «верхняя полусредняя длина». По верхней полусредней длине определяют тип и код волокна, определяющих цену на волокно.

Анализ гибридов $F_{2}$ по длине волокна показал, что при скрещивании линий и сортов с различным происхождением в ряде комбинаций выщепляются формы с длинным волокном. Например, высокие средние значения признака наблюдались в комбинациях $\mathrm{F}_{2}$ Л-578 х S-6082 (1,28 дюйм), $\mathrm{F}_{2}$ Л578 x S-489 (1,27 дюйм), F Л-Т х S-6003 (1,26 дюйм), F Л-Ю х S-6596 (1,25 дюйм), $\mathrm{F}_{2}$ Л-578 x S-6593 (1,23 дюйм) (табл. 1). Наибольший коэффициент вариации по длине волокна наблюдался в комбинациях $\mathrm{F}_{2}$ Л-Т х S-2515 ( $C v$ 7,5 \%), , $\mathrm{F}_{2}$ Л-Ю x S-6082 (Cv 6,0 \%), $\mathrm{F}_{2}$ Л-Ю x S-6593 (Cv 6,1 \%).

Таблица 1 - Изменчивость параметров качества волокна у гибридов $\mathrm{F}_{2}$

\begin{tabular}{|c|c|c|c|c|c|c|c|c|c|}
\hline $\begin{array}{l}\text { Гибридные } \\
\text { комбинации }\end{array}$ & $\mathrm{n}$ & Len & $C v, \%$ & Mic & $C v, \%$ & Str & $C v, \%$ & SCI & $C v, \%$ \\
\hline 1 & 2 & 3 & 4 & 5 & 6 & 7 & 8 & 9 & 10 \\
\hline $\mathrm{F}_{2} Л-578 \mathrm{x} \mathrm{S}-6003$ & 63 & 1,23 & 3,0 & 4,6 & 6,5 & 38,5 & 11,7 & 169,5 & 10,3 \\
\hline $\mathrm{F}_{2}$ Л-Т x S-6003 & 72 & 1,26 & 4,3 & 4,2 & 10,2 & 39,7 & 4,9 & 182,2 & 7,2 \\
\hline $\mathrm{F}_{2} Л-Ю \times$ × S-6003 & 48 & 1,23 & 2,2 & 3,9 & 3,6 & 38,3 & 3,8 & 176,9 & 0,8 \\
\hline $\mathrm{F}_{2} Л-578 \times \mathrm{S}-2515$ & 61 & 1,22 & 4,1 & 4,3 & 6,7 & 36,0 & 5,8 & 162,8 & 6,9 \\
\hline $\mathrm{F}_{2} Л-\mathrm{T}$ x S-2515 & 62 & 1,21 & 7,5 & 4,2 & 6,4 & 39,8 & 7,4 & 173,1 & 10,0 \\
\hline $\mathrm{F}_{2} Л-Ю \times$ x S-2515 & 48 & 1,23 & 4,1 & 4,3 & 10,7 & 35,8 & 11,1 & 166,6 & 10,1 \\
\hline $\mathrm{F}_{2}$ Л-578 x S-6082 & 62 & 1,28 & 0,7 & 4,5 & 8,8 & 40,3 & 1,1 & 171,3 & 9,3 \\
\hline $\mathrm{F}_{2}$ Л-Т x S-6082 & 35 & 1,14 & 5,3 & 4,6 & 8,9 & 37,3 & 5,2 & 171,5 & 0,9 \\
\hline F2Л-Ю × S-6082 & 66 & 1,19 & 6,0 & 4,3 & 9,6 & 36,7 & 13,5 & 166,4 & 12,4 \\
\hline $\mathrm{F}_{2} Л-578 \times$ S-489 & 71 & 1,27 & 4,9 & 4,1 & 8,7 & 33,7 & 3,6 & 169,6 & 7,1 \\
\hline
\end{tabular}




\begin{tabular}{|c|c|c|c|c|c|c|c|c|c|}
\hline 1 & 2 & 3 & 4 & 5 & 6 & 7 & 8 & 9 & 10 \\
\hline $\mathrm{F}_{2}$ Л-T x S-489 & 65 & 1,19 & 4,2 & 4,1 & 10,0 & 33,0 & 7,8 & 158,5 & 9,5 \\
\hline $\mathrm{F}_{2} Л-Ю \times \mathrm{S}-489$ & 52 & 1,16 & 0,6 & 4,0 & 3,5 & 31,9 & 0,4 & 150,8 & 1,4 \\
\hline $\mathrm{F}_{2} Л-578 \times \mathrm{S}-6593$ & 64 & 1,23 & 5,2 & 3,9 & 11,7 & 34,2 & 6,2 & 169,7 & 7,5 \\
\hline $\mathrm{F}_{2} Л-\mathrm{T}$ x S-6593 & 62 & 1,21 & 5,2 & 4,0 & 7,5 & 34,0 & 3,7 & 167,4 & 5,9 \\
\hline $\mathrm{F}_{2} Л-Ю \times$ S-6593 & 65 & 1,18 & 6,1 & 4,0 & 4,6 & 33,6 & 2,9 & 158,4 & 4,2 \\
\hline $\mathrm{F}_{2} Л-578 \times \mathrm{S}-6596$ & 74 & 1,22 & 3,7 & 4,4 & 8,2 & 34,2 & 6,1 & 159,9 & 7,5 \\
\hline $\mathrm{F}_{2} Л-\mathrm{T} \times \mathrm{S}-6596$ & 64 & 1,22 & 3,4 & 4,1 & 9,7 & 35,4 & 9,5 & 168,8 & 10,6 \\
\hline $\mathrm{F}_{2} Л-Ю$ x S-6596 & 73 & 1,25 & 2,7 & 4,0 & 5,4 & 35,4 & 3,6 & 171,7 & 2,7 \\
\hline St. Наманган-77 & 34 & 1,15 & 1,7 & 4,4 & 3,1 & 31,2 & 2,1 & 145,8 & 1,9 \\
\hline St. C-6524 & 37 & 1,17 & 2,1 & 4,3 & 2,8 & 39,9 & 2,4 & 175,3 & 2,6 \\
\hline
\end{tabular}

Микронейр - показатель, характеризующий тонину и зрелость хлопкового волокна. Для I и II сортов хлопкового волокна допустимый диапазон $3,5-4,9$ мк/дюйм. Ниже 3,5 волокно считается незрелым, в нем мало целлюлозы. Выше 4,9 - перезрелое, грубое. Допустимый диапазон микронейра для упландов без каких-либо штрафных санкций цены от 3,5 до 4,9, с диапазоном премиум 3,7 до 4,2 (Bradow и Davidonis, 2000) [6].

В наших опытах микронейр волокна в большинстве комбинаций соответствовал характеристике «среднее волокно» и составил от 4,0 до 4,6 мкг/дюйм. В комбинациях $\mathrm{F}_{2} Л-Ю$ х S-6003 и $\mathrm{F}_{2} Л-578$ х S-6593 средний показатель микронейра равнялся 3,9 , что соответствует характеристике «тонкое волокно». Наибольшая вариабельность признака проявилась в комбина-

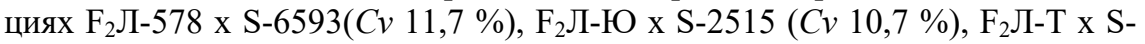
6003 ( $C v 10,2 \%)$ и $\mathrm{F}_{2} Л-\mathrm{T}$ x S-489 (Cv 10,0 \%). Таким образом, взятые нами в скрещивания интрогрессивные линии, а также линии производные от них являются донорами хорошего качества волокна.

Удельная разрывная нагрузка является одним из основных показателей, используемых для характеристики качества волокна и обозначает наибольшее усилие, выдерживаемое волокном до разрыва, выражается в гс/текс (грамм-силе на текс) [5].

У изученных комбинаций удельная разрывная нагрузка значительно превосходила стандартные сорта и колебалась в пределах от 31,9 до 40,3 гс\текс, что соответствует классу «очень крепкое волокно». Высокие показатели удельной разрывной нагрузки волокна отмечены в комбинациях $\mathrm{F}_{2}$ Л578 х Л-6082 - 40,2 гс/текс и F Л-Т х S-2515 - 39.8 гс/текс. Наибольший коэффициент вариации наблюдался в комбинациях $\mathrm{F}_{2}$ Л-Ю х S-6082 (Cv 13,5 $\%), \mathrm{F}_{2} Л-578 \mathrm{x}$ S-6003(Cv 11,7 \%) и $\mathrm{F}_{2}$ Л-Ю x S-2515(Cv 11,1 \%).

Расчетная прочность пряжи (SCI) - это расчет для прогнозирования общего качества и прядильности хлопкового волокна. Уравнение множественной регрессии может предоставить ценную информацию для прогнозирования прочности пряжи и потенциала вращения. 
В уравнении регрессии используется большинство отдельных результатов измерений HVI для расчета SCI. Этот индекс может быть использован для упрощения системы категорий, используемой при оценке хлопко-волокна. Как правило, чем выше индекс, тем выше прочность пряжи и тем лучше общие прядильные качества волокна [7]. Показатель SCI варьировал от 150,8 у F 2 Л-Ю х S-489 до 182.2 у комбинации $\mathrm{F}_{2} Л-\mathrm{T}$ х S-6003.

В результате браковки из 18 комбинаций $\mathrm{F}_{2}$ нами были отобраны 14. В третьем поколении у изученных гибридных комбинаций длина волокна была в пределах 1,18-1,28 дюйма, исключением стали две гибридные комбинации $\mathrm{F}_{3}$ Л-578 x S-6593 и F 3 Л-T х S-6596, длина волокна которых составила 1,12 и 1,15 дюйма соответственно (табл. 2). Наибольшая длина была характерна гибридам $\mathrm{F}_{3}$ Л-578 x S-489 - 1,28 дюйма, $\mathrm{F}_{3}$ Л-578 x S-6082 - 1,27 дюйма и $\mathrm{F}_{3}$ Л-Т x S-6593 - 1,26 дюйма. Эти данные свидетельствуют о высокой донорской способности по длине волокна интрогрессивной линии Л-Т, полученной с участием G. trilobum Skovsted, а также линии Л-578, производной от нее.

Таблица 2 - Изменчивость параметров качества волокна у гибридов $\mathrm{F}_{3}$

\begin{tabular}{|c|c|c|c|c|c|c|c|c|c|}
\hline $\begin{array}{l}\text { Гибридные } \\
\text { комбинации }\end{array}$ & $\mathrm{n}$ & Len & $\begin{array}{l}C v, \\
\%\end{array}$ & Mic & $\begin{array}{l}C v, \\
\%\end{array}$ & Str & $\begin{array}{l}C v, \\
\%\end{array}$ & SCI & $\begin{array}{l}C v, \\
\%\end{array}$ \\
\hline $\mathrm{F}_{3}$ Л-578xЛ-6003 & 44 & 1,21 & 2,6 & 4,5 & 6,3 & 35,1 & 4,9 & 163,8 & 8,5 \\
\hline $\mathrm{F}_{3}$ Л-T x S -6003 & 68 & 1,24 & 4,7 & 4,1 & 4,4 & 34,5 & 4,9 & 172,6 & 7,2 \\
\hline FЗЛ-578 xS-2515 & 56 & 1,24 & 2,4 & 4,2 & 8,5 & 33,2 & 5,5 & 179,4 & 5,5 \\
\hline $\mathrm{F}_{3}$ Л-Т x S -2515 & 60 & 1,21 & 5,2 & 4,5 & 3,8 & 35,0 & 5,3 & 161,8 & 4,8 \\
\hline $\mathrm{F}_{3}$ Л-578 xS-6082 & 57 & 1,27 & 0,6 & 4,6 & 2,8 & 38,0 & 6,1 & 177,2 & 3,1 \\
\hline $\mathrm{F}_{3}$ Л-Ю × S -6082 & 38 & 1,22 & 3,9 & 4,6 & 9,5 & 35,2 & 4,3 & 159,3 & 11,2 \\
\hline F3Л-578 x S-489 & 57 & 1,28 & 7,1 & 4,2 & 7,2 & 34,3 & 4,0 & 158,9 & 5,5 \\
\hline FЗЛ-Т x S-489 & 67 & 1,18 & 4,4 & 4,7 & 5,3 & 31,6 & 9,3 & 149,8 & 8,0 \\
\hline F3Л-578 xS-6593 & 67 & 1,12 & 0,8 & 4,5 & 3,3 & 32,2 & 3,4 & 156,3 & 3,6 \\
\hline F & 51 & 1,26 & 1,9 & 3,9 & 5,2 & 34,4 & 3,2 & 163,7 & 3,4 \\
\hline $\mathrm{F}_{3}$ Л-Ю х S-6593 & 91 & 1,21 & 0,8 & 4,4 & 2,2 & 34,5 & 2,3 & 157,2 & 1,6 \\
\hline F Л 578 xS-6596 & 72 & 1,20 & 5,1 & 4,8 & 7,4 & 32,7 & 2,4 & 142,1 & 6,2 \\
\hline F3Л-Т х S-6596 & 44 & 1,15 & 2,8 & 4,7 & 3,0 & 33,5 & 2,6 & 146,5 & 6,7 \\
\hline $\mathrm{F}_{3} Л-Ю \times$ × S-6596 & 68 & 1,18 & 2,7 & 4,4 & 4,0 & 33,1 & 4,3 & 154,7 & 9,4 \\
\hline St. Наманган-77 & 24 & 1,11 & 1,2 & 4,5 & 2,3 & 30,7 & 1,6 & 127,1 & 2,6 \\
\hline St. C-6524 & 35 & 1,13 & 1,3 & 4,3 & 2,1 & 35,1 & 1,9 & 157,9 & 3,2 \\
\hline
\end{tabular}

Максимальный микронейр волокна 4,8 мкг/дюйм наблюдался в гибридной комбинации $\mathrm{F}_{3}$ Л-578 x S-6596, у гибридов $\mathrm{F}_{3}$ Л-Т х S-489 и F $Л-Т$ х S-6596 4,7 мкг/дюйм. У остальных комбинаций данный показатель располагался в оптимальном промежутке 3,9-4,6 мкг/дюйм. Самое крепкое волокно отмечено у гибридной комбинации $\mathrm{F}_{3}$ Л-578 x Л-6082 - 38 гс/текс. Удельная 
разрывная нагрузка у остальных изученных гибридов соответствовала характеристике «очень высокая разрывная нагрузка волокна» (т.е. выше выше 31 гс/текс) и колебалась от 31,6 до 35,2 гс/ текс.

Показатель расчетной прочности пряжи был наименьшим у $\mathrm{F}_{3}$ Л-578 x S-6596 - 142,1. Наибольший показатель наблюдался у F 3 Л-578 x S-2515 179,4. Среди гибридов встречаются рекомбинанты с индексом прочности пряжи 180-190.Отмечено, что прядильные качества в большей степени зависят от удельной разрывной нагрузки волокна.Полученные данные позволяют выделить комплексно-ценные комбинации по качеству волокна.

\section{Список литературы}

1. Алиходжаева С.С., Мунасов Х., Муратов У.М. Дикие и рудеральные формы хлопчатника вида Gossypium hirsutum L. / С.С. Алиходжаева, Х. Мунасов, У.М. Муратов // Ташкент: Университет, 1992. - 60 с.

2. Доспехов В.А. Методика полевого опыта / В.А. Доспехов // М.: Колос, 1979. $-416 \mathrm{c.}$

3. Лемешев Н. Мировой фонд на службу хлопководства / Н. Лемешев // Хлопководство. 1984 - № 6. - С. 40-42.

4. Семенихина Л.В., Гуревич Л.И., Эгамбердиев А.Э. Проявление контрастных признаков у гибридов хлопчатника $\mathrm{F}_{1}$ и амфидиплоидов $\mathrm{K}_{1}, \mathrm{~K} 2$ G. hirsutum L. х G. trilobum Skovst. / Л.В. Семенихина, Л.И. Гуревич, А.Э. Эгамбердиев // Генетика. 1979. - Т. 15. - № 11. - С. 2013-2016.

5. Устюгин В.Е., Максудов И.Т., Урунов Н.Д. Волокно хлопковое. Технические условия / В.Е. Устюгин, И.Т. Максудов, Н.Д. Урунов // Ташкент: Изд. «Сифат», 1999. $-31 \mathrm{c}$.

6. Bradow, J.M., G.H. Davidonis. Quantitation of fiber quality and the cotton production-processing interface: a physiologist's perspective [electronic resource] / J.M.Bradow, Davidonis G.H. // Journal of cotton science (Online) Journal of cotton science 2000. 4: 34-64.

7. Abhijit Majumdar, Prabal Kumar Majumdar*, Bijon Sarka Selecting cotton bales by spinning consistency index and micronaire using artificial newral networks.AUTEX Research Journal, Vol. 4, No1, March 2004.

DOI 10.18699/GPB2020-68

\section{Изучение структуры популяции гриба бурой ржавчины пшеницы в лесостепи Приобья Новосибирской области в 2017-2019 гг.}

Сочалова Л.П., с.н.с.; Пискарев В.В. *, зав. лабораторией; Бойко Н.И., м.н.с. Сибирский научно-исследовательский институт растениеводства и селекции - филиал Федерального исследовательского центра «Институт циитологии и генетики Сибирского отделения РАН», п. Краснообск, Россия. *еmail: piskaryov_v@mail.ru

По результатам мониторинга популящии Р. recondita на территории 